\title{
JNPH
}

Volume 5 No. 2 (Desember 2017)

(C) The Author(s) 2017

\section{APLIKASI MODEL KONSEP KEPERAWATAN CALISTA ROY PADA TN. N POST OP HERNIA INGUINALIS DI RUANGAN SAFA RS.KOTA BENGKULU PROVINSI BENGKULU}

\author{
APPLICATION OF MODEL NURSING CONCEPT OF CALISTA ROY ON TN. N \\ POST OP HERNIA INGUINALIS AT SAFA ROOM IN BENGKULU CITY HOSPITAL \\ BENGKULU PROVINCE
}

\author{
SURYANTI \\ UPTD PUSKESMAS KANDANG KOTA BENGKULU \\ Email: Suryantifdma77@gmail.com
}

\begin{abstract}
ABSTRAK
Hernia merupakan prostusi atau penonjolan isi rongga melalui defek atau bagian lemah dari dinding rongga bersangkutan. Hernia disebabkan karena adanya tekanan intra abdomen seperti batuk dan mengejan. Hernia apabila tidak segera ditangani akan menyebabkan terjadinya perlengketan antara isi hernia dengan dinding kantong hernia sehingga isi hernia tidak dapat dikembalikan lagi. Penderita hernia memang kebanyakan laki-laki, kebanyakan penderitanya akan merasa nyeri, jika terjadi infeksi didalamnya. Hernia yang terjadi pada anak - anak lebih disebabkan karena kurang sempurnanya procesus vaginalis untuk menutup seiring dengan turunnya testis atau buah zakar. Sementara pada orang dewasa, karena adanya tekanan yang tinggi dalam rongga perut dan karena faktor usia yang menyebabkan lemahnya dinding otot perut.Teori adaptasi Calista Roy merupakan model keperawatan yang menguraikan bagaimana individu mampu meningkatkan kesehatan dengan cara mempertahankan perilaku adaptif serta mampu merubah perilaku yang inadaptif. Jenis studi kasus ini adalah studi kasus post op hernia inguinalis dengan aplikasi teori Calista Roy dengan menggunakan metode deskriptif yaitu suatu metode yang dilakukan dengan tujuan utama untuk membuat gambaran atau deskripsi tentang suatu keadaan secara obyektif dan memusatkan perhatian pada objek tertentu. Hasil penelitian didapatkan keefektifan dalam teori Calista Roy pada post op hernia inguinalis ini yaitu mengajarkan klien untuk beradaptasi baik adaptasi prilaku maupun fisiologi, dimana Tn. N dapat beradaptasi baik internal dan eksternal, dengan melaksanakan implementasi yang diberikan dengan mengacu pada adaptasi untuk mencapai derajat optimal yang telah disampaikan dapat dilakukan dengan Tn. N secara bertahap. Dimana pelaksanaan tindakan dilakukan selama 6 hari dan pada hari pertama pelaksanaan tindakan cara mengatasi nyeri pada daerah post op saat beraktifitas dan pada hari ke 6 semua implementasi dapat dipahami dan dilakukan untuk memenuhi kebutuhan aktivitas klien dan prilaku pola makan yang baik, lebih memfokuskan untuk mencoba mengubah prilaku klien dalam mengatasi masalah. Secara khusus, perawat harus mampu meningkatkan respon adaptif pasien pada situasi sehat atau sakit. Perawat mampu mengambil tindakan untuk memanipulasi stimuli fokal, kontektual, maupun residual stimuli dengan melakukan analisa sehingga stimuli berada pada daerah adaptasi. Perawat harus mampu bertindak untuk mempersiapkan pasien mengantisipasi perubahan melalui penguatan regulator, kongnator dan mekanisme koping yang lain.
\end{abstract}

Kata Kunci: post op hernia inguinalis, teori calista roy 


\begin{abstract}
Hernia is a prosthesis or protrusion of the contents of the cavity through a defect or a weak portion of the cavity wall in question. Hernias are caused by intra-abdominal pressure such as coughing and straining. Hernia if not treated immediately will cause adhesion between the contents of the hernia with a hernia pouch wall so that the contents of the hernia can not be restored again. Patients with hernias are mostly male, most sufferers will feel pain, if there is infection in it. Hernia that occurs in children is more due to lack of perfect procesus vaginalis to close along with the decline of the testes or testicles. While in adults, due to the high pressure in the abdominal cavity and due to age factors that cause weakness of the abdominal muscle wall. Calista Roy adaptation theory is a model of nursing that describes how individuals can improve health by maintaining adaptive behavior and able to change behavior that adaptive. This case study type is case study of post op hernia inguinalis with application of Calista Roy theory by using descriptive method that is a method done with main aim to create picture or description about a situation objectively and concentrate on certain object. The results of this research show that effectiveness in Calista Roy's theory of post inguinal hernia is to teach the client to adapt both behavioral and physiological behaviors. $\mathrm{N}$ can adapt both internally and externally, by implementing the given implementation with reference to adaptation to achieve the optimum degree that has been delivered can be done with Tn. $\mathrm{N}$ gradually. Where the implementation of the action carried out for 6 days and on the first day of the implementation of action how to deal with pain in the post op area during activity and on day 6 all implementations can be understood and done to meet the needs of client activities and good eating habits, focusing on trying to change client behavior in troubleshooting. In particular, the nurse must be able to improve the patient's adaptive response to a healthy situation or illness. The nurse is able to take action to manipulate the focal, contextual, and residual stimuli stimuli by performing an analysis so that the stimuli are in the adaptation area. Nurses should be able to act to prepare patients to anticipate changes through strengthening regulators, conglomerates and other coping mechanisms.
\end{abstract}

Keywords: post op hernia inguinalis, calista roy theory

\section{PENDAHULUAN}

Masyarakat modern saat ini sering mengalami masalah kesehatan terutama kesehatan pada pencernaan. Pencernaan bukan hanya memperhatikan bagaimana kebutuhan makanan dapat terpenuhi melainkan juga memperhatikan bagaimana proses metabolic dapat berlangsung dengan baik, sehingga pencernaan dapat di asumsikan sebagai sebuah proses metabolic dimana saat mahluk hidup memproses secara kimiawi maupun mekanik sebuah zat menjadi nutrisis yang di butuhkan oleh tubuh. Akan tetapi apabila terjadi perubahan pada proses ini maka akan terjadi ganguan pencernaan yang salah satunya adalah hernia (Reksoprodjo,2007)

Hernia inguinalis merupakan

permasalahan yang biasa ditemukan dalam kasus bedah. Kasus kegawatdaruratan dapat terjadi apabila hernia inguinalis bersifat strangulasi (ireponibel disertai gangguan pasase) dan inkarserasi (ireponibel disertai gangguan vascularisasi). Inkarserasi merupakan penyebab obstruksi usus nomor satu dan tindakan operasi darurat nomor dua setelah apendicitis akut di Indonesia (Sjamsuhidajat, 2010 dan Greenberg et al, 2008).

Berdasarkan laporan WHO dari data NHS, melaporkan bahwa pada tahun 20012002 ada sekitar 70.000 operasi hernia inguinal telah dilakukan di Inggris dan melibatkan $0,14 \%$ dari populasi, dan membutuhkan lebih dari 100.000 NHS rumah sakit tempat tidur hari. Dari prosedur ini, 62.969 adalah untuk perbaikan hernia primer 
dan 4939 adalah untuk perbaikan hernia berulang.

Insiden hernia merupakan antara insiden yang paling sering terjadi di Amerika Serikat pada tahun 2009 dimana sekitar 700.000 operasi hernia yang dilakukan setiap tahun. Bedasarkan survey yang dilakukan di Amerika Serikat Hernia Inguinalis merupakan penyakit peringkat kelima di AS. Hernia inguinalis merupakan satu penyebab dari masalah bedah yang paling sering dijumpai pada masa bayi dan anak.

Di Amerika Serikat, perkiraan berdasarkan data cross-sectional ditunjukkan bahwa sekitar 700.000 perbaikan hernia inguinalis yang dilakukan pada tahun 1993. Hernia Inguinalis di sisi kanan adalah tipe hernia yang paling banyak dijumpai pria dan wanita,dimana sekitar $25 \%$ pria dan $2 \%$ wanita mengalami hernia inguinalis. Angka kejadian Hernia inguinalis lateralis di Amerika dapat di mungkinkan dapat terjadi karena anomali congenital.

Suatu survey nasional dari praktek umum, meliputi sekitar $1 \%$ dari populasi Inggris dan Wales tahun 1991-1992, menemukan bahwa sekitar 95\% dari orang yang datang ke fasilitas pelayanan primer dengan hernia inguinalis adalah lakilaki.Sebuah jumlah yang sama dari perbaikan hernia inguinalis yang dilakukan dalam pengaturan kesehatan publik di Inggris pada tahun 2002-2003.

Menurut data dari National Center for Health Statistics, Hernia Inguinalis menduduki peringkat pertama lima besar tindakan operasi yang paling banyak dilakukan oleh ahli bedah Amerika pada tahun 1991 yaitu sebanyak 680.000 kasus (Eubanks, 2001). Penelitian terhadap 2.538 veteran pemerintah di Amerika yang menjalani Hernioraphy pada tahun 1966-1980 memperlihatkan 57\% kasus Hernia Inguinalis Lateralis (Kong \& Hiatt, 2007).

Di Indonesia hernia menempati urutan kedelapan dengan jumlah 292.145 kasus. Angka kejadian hernia inguinalis (medialis/direk dan lateralis/indirek) $10 \mathrm{kali}$ lebih banyak daripada hernia femoralis dan keduanya mempunyai persentase sekitar 75$80 \%$ dari seluruh jenis hernia, hernia insisional $10 \%$, hernia ventralis $10 \%$, hernia umbilikalis $3 \%$, dan hernia lainnya sekitar 3 $\%$ (Sjamsuhidajat, 2010 dan Lavelle et al, 2002). Secara umum, kejadian hernia inguinalis lebih banyak diderita oleh laki-laki dari pada perempuan. Angka perbandingan kejadian hernia inguinalis $13,9 \%$ pada lakilaki dan 2,1\% pada perempuan (Ruhl, 2007).

Peningkatan angka kejadian Hernia Inguinalis di Indonesia banyak terjadi daerah provinsi Jawa Tengah bisa disebabkan karena ilmu pengetahuan dan tehnologi semakin berkembang dengan pesat sejalan dengan hal tersebut, maka permasalahan manusiapun semakin kompleks salah satunya kebutuhan ekonomi yang semakin mendesak (Haryono, 2012).

Hal tersebut menuntut manusia untuk berusaha mencukupi kebutuhannya dengan usaha yang ekstra, tentunya itu mempengaruhi pola hidup dan kesehatannya yang dapat menyebabkan kerja tubuh yang berat yang dapat menimbulkan kelelahan dan kelemahan dari berbagai organ tubuh. Penyebab penyakit hernia yaitu dengan bekerja berat untuk memenuhi kebutuhannya seperti mengangkat beban berat, biasa mengkonsumsi makanan kurang serat, yang menyebabkan konstipasi sehingga mendorong mengejan saat defekasi. (Haryono,2012)

Hernia merupakan prostusi atau penonjolan isi rongga melalui defek atau bagian lemah dari dinding rongga bersangkutan. Hernia disebabkan karena adanya tekanan intra abdomen seperti batuk dan mengejan. Hernia apabila tidak segera ditangani akan menyebabkan terjadinya perlengketan antara isi hernia dengan dinding kantong hernia sehingga isi hernia tidak dapat dikembalikan lagi. Penderita hernia memang kebanyakan laki-laki, kebanyakan penderitanya akan merasa nyeri, jika terjadi infeksi didalamnya. Hernia yang terjadi pada anak - anak lebih disebabkan karena kurang sempurnanya procesus vaginalis untuk menutup seiring dengan turunnya testis atau buah zakar. Sementara pada orang dewasa, 
karena adanya tekanan yang tinggi dalam rongga perut dan karena faktor usia yang menyebabkan lemahnya dinding otot perut. (Liu \& Campbell,2011)

Teori adaptasi Calista Roy merupakan model keperawatan yang menguraikan bagaimana individu mampu meningkatkan kesehatan dengan cara mempertahankan perilaku adaptif serta mampu merubah perilaku yang inadaptif. Teori adaptasi Calista Roy sudah diterapkan pada pasien dengan berbagai macam penyakit di RSUPN Dr.Cipto Mangunkusomo Jakarta tahun 2014. Teori Aplikasi Roy ini telah diterapkan pada Ny. P dengan kasus anemia di RT 5 Rawa Makmur Kota Bengkulu Oleh Zelyanti 2016.

Penerapan teori ini akan membantu seseorang beradaptasi terhadap perubahan kebutuhan fisiologis, konsep diri, fungsi peran dan interdependensi selama sehat dan sakit (Tomey \& Alligood,2007). Pendekatan asuhan keperawatan dengan menggunakan pendekatan teori adaptasi Calista Roy dipandang sangat ideal untuk diterapkan dalam memberikan pelayanan asuhan keperawatan professional terutama pada pasien dengan penyakit kronis yang memerlukan adaptasi panjang terhadap perubahan status kesehatannya.

\section{METODE PENELITIAN}

Jenis studi kasus ini adalah studi kasus post op hernia inguinalis dengan aplikasi teori Calista Roy dengan menggunakan metode deskriptif yaitu suatu metode yang dilakukan dengan tujuan utama untuk membuat gambaran atau deskripsi tentang suatu keadaan secara obyektif dan memusatkan perhatian pada objek tertentu (Notoatmojo, 2010).

\section{HASIL PENELITIAN}

Aplikasi teori Calista Roy dalam pemberian asuhan keperawatan pada Tn. N dengan Post op Hernia Inguinalis. Dalam Bab ini, penulis akan membahas meliputi segi pengkajian, diagnosa, perencanaan keperawatan, implementasi keperawatan, dan evaluasi keperawatan mengenai kasus yang penulis angkat.

\section{Tahap Pengkajian}

Pengkajian juga disebut sebagai pengumpulan data adalah langkah awal dalam berfikir kritis dan pembuat keputusan yang mengarah pada diagnosis keperawatan. Menurut dermawan \& rahayuningsih (2010) hal yang perlu dikaji pada penderita hernia inguinalis adalah memiliki riwayat pekerjaan mengangkat beban berat, duduk terlalu lama, terdapat benjolan pada bagian yang sakit, kelemahan otot, nyeri tekan, keluhan nutrisi tidak terpenuhi karena nyeri pada perut

Penulis melakukan pengkajian pada Tn.N berdasarkan proses pengkajian melalui proses wawancara dengan keluarga dan observasi pada klien. Pengkajian dilakukan di dapatkan data yaitu nama pasien Tn.N, umur 57 th, alamat J1. Sepakat kel. Kampung Melayu kota Bengkulu, pekerjaan kuli bangunan, pendidikan SD, pengkajian pada pasien terdapat nyeri pada abdomen bawah kanan, terdapat bekas luka post op hernia inguinalis, klien tampak meringis menahan kesakitan, dari pengkajian pola makan klien tidak teratur, biasanya $3 \mathrm{x}$ sehari dengan porsi normal, menjadi $3 \mathrm{x}$ sehari setengah porsi biasa.

Dalam pengkajian klien Calista Roy menganjurkan klien beradaptasi terhadap prilaku dan fisiologi. Dia melakukan pengamatan yang tepat mengenai semua aspek kesehatan fisik klien dari prilaku, ia mencatat bahwa observasi (pengkajian) bukan demi berbagai informasi/ fakta yang mencurigakan, tetapi demi menyelamatkan hidup dan meningkatkan kesehatan dan keamanan. Lazarus (1966) mencatat bahwa konsep Calista Roy mengkombinasikan teori adaptasi helson dengan definisi dan pandangan terhadap manusia sebagai system yang adaptif. Selain konsep-konsep tersebut Roy juga mengadaptasi nilai humanisme dalam model konseptualnya berasal dari konsep A.H Maslow untuk mengalih 
keyakinan dan nilai dari manusia. Menurut Roy humanisme dalam keperawatn adalah keyakinan terhadap kemampuan koping masyarakat yang dapat meningkatkan derajat kesehatan.

Nursalam (2008), pengkajian keperawatan dalam tahap awal dari proses keperawatan dan merupakan suatu proses pengumpulan data yang sistematis dari berbagai sumber untuk mengevaluasi dan mengindentifikasi status kesehatan klien. Informasi yang didapat dari klien (sumber data primer), data yang didapat dari orang lain (data sekunder), catatan kesehatan klien, informasi atau laporan laboratorium, tes diagnostic keluarga dan orang yang terdekat atau anggota tim kesehatan merupakan pengkajian data dasar.

\section{Diagnosa Keperawatan}

Data yang di peroleh terdapat bekas luka post op hernia inguinalis sehingga klien sering merasakan nyeri dan sulit bergerak. Diagnosa yang dapat di rumuskan adalah Gangguan fisiologis (neurologis) berhubungan dengan ketidakmampuan pasien dalam beradaptasi terhadap luka operasi. Data kedua yang diperoleh adalah pola makan klien yang tidak teratur dari klien makan $3 \mathrm{x}$ sehari porsi normal menjadi 3x sehari setengah porsi biasanya. Diagnose selanjutnya yaitu Inadekuat intake nutrisi berhubungan dengan ketidak mampuan pasien beradaptasi terhadap gangguan nutrisi.

Diagnosa keperawatan adalah sebuah label singkat yang mengambarkan kondisi pasien yang di observasi di lapangan. Kondisi ini dapat berupa masalah-masalah actual atau potensial (wikinson,2008)

\section{Intervensi Keperawatan}

Rancana intervensi harus dilakukan sesuai masalah serta akan dilakukan selama $5 \times 24$ jam. Rencana asuhan keperawatan kepada keluarga dengan gangguan fisiologis (neurologi) b.d ketidakmampuan pasien dalam beradaptasi terhadap luka operasi.
Dengan tujuan setelah dilakukan tindakan keperawatan selama $5 \times 24$ jam klien dapat beradaptasi dengan rasa nyeri dengan melakukan perawatan yang optimal. Dan kriteria hasil klien mampu melakukan aktivitas dengan baik. Keluarga dapat melakukan perawatan pada anggota keluarga yang sakit.

Intervensi yang dapat disusun berikan pengetahuan kepada pasien, dan anggota keluarga pasien yang menderita post op hernia inguinalis, berikan pengetahuan kepada anggota keluarga tentang cara membantu pasien untuk beraktifitas agar pasien tidak merasa nyeri, bimbing keluarga untuk selalu mengontrol aktivitas pasien. Calista Roy (1989) menyatakan bahwa prilaku sangat penting untuk kesehatan baik internal maupun ekternal.

Perencanaan difokuskan pada adaptasi prilaku untuk meningkat kesehatan klien. Hal ini tidak sejalan dengan pendapat Wong (2004), rencana kegiatan merupakan serangkai kegiatan atau intervensi untuk mencapai tujuan pelaksanaan asuhan keperawatan.Intervensi keperawatan adalah preskrpsi untuk prilaku pesifik yang diharapkan oleh pasien dan atau tindakan yang harus dilakukan oleh perawat. Perencanaan adalah kategori dari perilaku keperawatan dimana tujuan yang berpusat pada klien dan hasil yang diperkirakan ditetapkan dan diintervensi keperawatan dipilih untuk mencapai tujuan tersebut (Potter \& Perry, 2005).

\section{PEMBAHASAN}

\section{Implementasi Keperawatan}

Dalam melakukan implementasi yang akan diberikan pada keluarga Tn. $\mathrm{N}$ penulis mengambil data yaitu dengan menyesuaikan interval yang telah direncanakan untuk diagnosa keperawatan gangguan fisiologis (neurologi) b.d ketidakmampuan pasien dalam beradaptasi terhadap luka operasi dan diagnosa Inadekuat nutrisi $\mathrm{b} / \mathrm{d}$ ketidak mampuan pasien beradaptasi terhadap 
gangguan nutrisi, meliputi mengkaji kemampuan pasien untuk melakukan aktifitas harian tanpa ada keluhan, kelemahan kesulitan beraktifitas dapat menimbulkan rasa nyeri, menjelaskan kepada pasien manfaat aktifitas bertahap, menganjurkan pasien untuk meningkatkan asupan nutrisi, dan memberikan pengetahuan kepada keluarga tentang memberikan asuhan keperawatan kepada anggota keluarga dengan post op hernia inguinalis. Memberikan pengetahuan keluarga dalam mengontrol aktivitas klien. Hal ini seperti dituangkan dalam penelitian Obral (1980) yang menyatakan ada hubungan antara prilaku dengan kejadian post op hernia inguinalis.

Hal ini sesuai dalam pernyatan Calista Roy yang menjelaskan bahwa, perilaku dapat mempengaruhi kekambuhan penyakit. Pelaksanaan terjadi pada klien yang mempengaruhi klien mencapai kesembuhan yang optimal, semua faktor prilaku harus dipertimbangkan, termasuk faktor keturunan, tingkat pengetahuan dan pola hidup. Proses pelaksanaan implementasi harus berpusat kepada kebutuhan klien, faktor-faktor lain yang mempengaruhi kebutuhan keperawatan, strategi implementasi keperawatan, dan kegiatan komunikasi (Konzier, 2010).

\section{Evaluasi Keperawatan}

Hasil evaluasi yang didapatkan pada diagnose keperawatan. Gangguan fisiologis (neurologi) b/d ketidak mampuan pasien dalam beradaptasi terhadap luka operasi. Data subjektif klien mengatakan sudah mengerti dengan apa yang sudah dijelaskan perawat,Asesmen: masalah dalam perbaikan, Palnning: intervensi dilanjutka. Evaluasi berdasarkan pada efek dari perubahan prilaku klien untuk mendapatkan kembali kesehatan mereka. Menurut Craven dan Hirnle (2000) evaluasi didefinisikan sebagai keputusan dari efektifitas asuhan keperawatan antara tujuan keperawatan klien yang telah ditetapkan dengan respon prilaku yang tampil.

\section{Keefektifan Teori Orem}

Keefektifan dalam teori Calista Roy pada post op hernia inguinalis ini yaitu mengajarkan klien untuk beradaptasi baik adaptasi prilaku maupun fisiologi, dimana Tn. $\mathrm{N}$ dapat beradaptasi baik internal dan eksternal, dengan melaksanakan inplementasi yang diberikan dengan mengacu pada adaptasi untuk mencapai derajat optimal yang telah disampaikan dapat dilakukan dengan Tn. N secara bertahap. Dimana pelaksanaan tindakan dilakukan selama 6 hari dan pada hari pertama pelaksanaan tindakan cara mengatasi nyeri pada daerah post op saat beraktifitas dan pada hari ke 6 semua implementasi dapat dipahami dan dilakukan untuk memenuhi kebutuhan aktivitas klien dan prilaku pola makan yang baik, lebih memfokuskan untuk mencoba mengubah prilaku klien dalam mengatasi masalah.

\section{Kelebihan Teori Orem}

Dengan penerapan dari teori adaptasi Roy perawat sebagai pemberi asuhan keperawatan dapat mengetahui dan lebih memahami individu, tentang hal-hal yeng menyebabkan stress pada individu, proses mekanisme koping dan effektor sebagai upaya individu untuk mengatasi stress. Keunggulan teori ini adalah dimana keluarga bisa melakukan adaptasi, sehingga bisa mengatasi perasaan yang terjadi pada pasien post op hernia teori Calista Roy ini difokuskan pada adaptasi perilaku dan fisiologis baik internal maupun eksternal.

\section{Kelemahan Teori Orem}

Kelemahan dari model adaptasi Roy ini adalah terletak pada sasaranya. Model adaptasi Roy ini hanya berfokus pada proses adaptasi pasien dan bagaimana pencegahan masalah pasien dengan menggunakan proses keperawatan dan tidak menjelaskan bagaimana sikap dan perilaku cara merawat (carring) pada pasien. Sehingga seorang perawat yang tidak mempunyai perilaku 
caring ini akan menjadi stressor bagi para pasienya.

\section{KESIMPULAN}

Intervensi dan implementasi yang ditegakkan oleh penulis sudah sesuai dengan teori Calista Roy sesuai diagnosa yang ditegakkan, implementasi dilakukan sesuai dengan rencana keperawatan yang disusun, disertai respon hasil dari pasien, tahap evaluasi dari diagnosa keperawatan yang penulis implementasikan selama 3 hari berhasil dilakukan, teori Model Roy efektif di aplikasikan pada pasien dengan kasus Post op Hernia Inguinalis.

\section{SARAN}

Secara umum pembaca diharapkan mampu menelaah dan mempelajari setiap konsep dan model keperawatan yang sudah berkembang dan mampu membandingkan teori dan model praktik yang sesuai dengan ilmu keperawatan itu sendiri sehingga tidak bertentangan dengan etika, norma dan budaya. Secara khusus, perawat harus mampu meningkatkan respon adaptif pasien pada situasi sehat atau sakit. Perawat mampu mengambil tindakan untuk memanipulasi stimuli fokal, kontektual, maupun residual stimuli dengan melakukan analisa sehingga stimuli berada pada daerah adaptasi. Perawat harus mampu bertindak untuk mempersiapkan pasien mengantisipasi perubahan melalui penguatan regulator, kongnator dan mekanisme koping yang lain.

Pada situasi sehat, perawat berperan untuk membantu pasien agar tetap mampu mempertahankan kondisinya sehingga integritasnya akan tetap terjaga. Misalnya melalui tindakan promotif perawat dapat mengajarkan bagaimana meningkatkan respon adaptifnya akibat adanya perubahan lingkungan baik internal maupun external.

\section{DAFTAR PUSTAKA}

Brunner \& Suddarth, 2001, Buku Ajar
Keperawatan Medikal Bedah, Edisi 8 Volume 2, Penerbit Buku Kedokteran EGC, Jakarta.

Dermawan, D., dan Rahayuningsih, T. 2010. Keperawatan Medikal Bedah Sistem Pencernaan. Yogyakarta: Gosyen Publishing.

Haryono, R. 2012. Keperawatan Medikal Bedah Kelainan Bawaan Sistem Pencernaan. Yogyakarta: Gosyen Publishing.

Lesti Elisa 2016 Aplikasi Teori Adaptasi Calista Roy dalam Pemberian ASKEP dengan Artritis Rematoid Kota Bengkulu

Liu, T., \& Campbell, A. 2011. Case Files Ilmu Bedah. Jakarta: Karisma Publishing Group.

Mansjoer, E, Doenges, 2012, Kapita Selekta Kedokteran. Edisi III, Jilid II, Penerbit Media Aesculapius FKUI, Jakarta.

Nanda. 2013. Diagnosis keperawatan: Definisi dan Klasifikasi. Jakarta: EGC.

Potter, P, A,. Perry, A., G. (2010). Fundamental Keperawatan: Konsep, Proses dan Praktik. Jakarta:EGC

Reksoprodjo, S. 2007. Kumpulan Kuliah Ilmu Bedah. Jakarta: Binarupa Aksara Publisher.

Roy S.C, Andrew H.A, The Roy Adaptation Model . The Defenitive Statement California : Appleton and Large 1991

R. Sjamsuhidayat, 1997, Ajar Ilmu Bedah, Penerbit Buku Kedokteran EGC, Jakarta

Sjamsuhidajat \& Jong. 2010. Buku Ajar Ilmu Bedah. Jakarta: Buku Kedokteran EGC.Nursalam. (2010). Manajemen Keperawatan: Aplikasi dalam Praktik Keperawatan Professional

Sudarmi 2016 Aplikasi Teori Adaptasi Calista Roy dalam Pemberian ASKEP dengan Anemia pada Ny. E di RT 5 Rawa Makmur Kota Bengkulu

Zelyanti 2016.Teori Aplikasi Teori Adaptasi Clista Roy Dalam Pemberian ASKEP dengan Anemia pada Ny. P di RT 5 Rawa Makmur Kota Bengkulu 